1992-06-01

\title{
Interface Cavitation Damage in Polycrystalline Copper
}

Brent L. Adams

b_I_adams@byu.edu

David P. Field

Follow this and additional works at: https://scholarsarchive.byu.edu/facpub

Part of the Mechanical Engineering Commons

Original Publication Citation

Acta Metallurgia et Materialia (USA). Vol. 4, no. 6, pp. 1145-1157. June 1992

\section{BYU ScholarsArchive Citation}

Adams, Brent L. and Field, David P., "Interface Cavitation Damage in Polycrystalline Copper" (1992).

Faculty Publications. 715.

https://scholarsarchive.byu.edu/facpub/715

This Peer-Reviewed Article is brought to you for free and open access by BYU ScholarsArchive. It has been accepted for inclusion in Faculty Publications by an authorized administrator of BYU ScholarsArchive. For more information, please contact ellen_amatangelo@byu.edu. 


\title{
INTERFACE CAVITATION DAMAGE IN POLYCRYSTALLINE COPPER
}

\author{
D.P. Field and B.L. Adams \\ Department of Mechanical Engineering, Yale University, \\ New Haven, CT 06520-2157
}

\begin{abstract}
Determination of an interface damage function (IDF) [1], from a stereological procedure similar to that presented by Hilliard [2], is described. The mathematical and experimental simplicity of the method is utilized in measuring an IDF for polycrystalline copper crept at $0.6 \mathrm{~T}_{\mathrm{m}}$ under uniaxial tension. Whereas previous work focussed on a five parameter description of the local state of a grain boundary, the domain of the IDF is increased to eight degrees of freedom in the present study to include the complete geometrical description of grain boundary structure. The resulting functions identify certain types of grain boundaries which were preferentially damaged. Most of the damage occurred on interfaces oriented nearly normal to the principal stress axis. Some relatively small angle boundaries demonstrated a surprising propensity to cavitate as did certain special boundaries distinguished by a group multiplicity in misorientation space greater than one. A sequence of two dimensional projections through the eightdimensional domain of the IDF is shown to identify a number of interface structures which are readily damaged.
\end{abstract}

\section{INTRODUCTION}

Damage on interfaces of polycrystalline materials, which have been subjected to various stress and ambient conditions, is commonly observed in the form of cracks and voids. Grain boundary damage is almost always heterogeneous in nature except under certain laboratory conditions where voids are intentionally distributed uniformly to study growth behavior (cf. $[3,4]$ ). This heterogeneity of damage prompts investigation into the 
character of interfaces which are preferentially damaged. Several authors have suggested that damage is a function of the misorientation of adjoining crystallites [1,5-7]. Factors which may contribute to damage heterogeneity such as the local stress field and the dislocation structure of the grain boundary, are sensitive to interface orientation and lattice misorientation. It has been shown that the grain boundary character of a polycrystalline sample can be altered with heat treatments or by applying alternate forming and processing techniques to improve specific properties of polycrystalline materials [8-10]. By isolating the types of interfaces which are most readily damaged, the processing and forming of materials may be altered to avoid these types of grain boundaries, thereby increasing the useful life of structural components.

In a previous paper [1] an interface damage function (IDF), defining area fraction of interface damage, was presented. Having functional dependence on five variables, the IDF was shown to be useful in identifying interface normal and crystallite lattice misorientation combinations which are preferentially damaged. The stereology of this method required sectioning a damaged specimen and measuring the fraction of damaged line lying at a given angle to a chosen reference line. The reader is referred to reference [1] along with Adams' earlier work discussing the measurement of an interface structure distribution function (ISDF) [11,12].

In the present investigation, a stereological approach developed by Hilliard [2] is taken to determine the IDF for copper specimens crept in uniaxial tension. The specimens and experimental conditions differ substantially from those used in the previous study [1]. We increase the domain of the IDF to include dependence upon individual crystallite lattice orientations instead of concentrating entirely on misorientations. The term IDF is used in this paper for functions which express the area fraction of damage, regardless of the variables defining the character of the boundary.

\section{A STEREOLOGICAL PROCEDURE TO MEASURE THE IDF}

Various procedures exist to measure surface area of crystallite interface in polycrystalline samples. Serial sectioning through the sample or thin film transmission electron microscopy (TEM) yield the desired information, but only after considerable experimental effort. On the other hand, stereological measures obtained through random sectioning may lead to mathematical complexities and numerical difficulties. We have adopted the method of Hilliard in the present work because of its mathematical and 
experimental simplicity. A comparison of Hilliard's method with Adams' work [1,11,12] is the subject of a separate paper [13].

\subsection{Finding Interface Area per Unit Volume using the Method of Hilliard}

Essential elements of Hilliard's method are reproduced here, as this procedure is not commonly known in the materials community. A polycrystal is sectioned and scans are made with random test lines through each section keeping track of grain boundary intersections of a given character per unit length. If it is believed that only the interface normal orientation is of importance in specifying the damage dependence of grain boundaries during creep, the measure $\mathrm{P}_{\mathrm{L}}(\mathbf{t})$, intersections per unit length of scan line in a direction $\mathbf{t}$, is sufficient. However, if the crystallographic structure of the interface is expected to be an important factor, the IDF may require information about lattice misorientation across the grain boundary or even the individual orientation of each crystallite composing the boundary, in which case we measure either $\mathrm{P}_{\mathrm{L}}(\Delta \mathrm{g} \mid \mathbf{t})$ or $\mathrm{P}_{\mathrm{L}}\left(\mathrm{g}, \mathrm{g}^{\prime} \mid \mathbf{t}\right)$ respectively. In this notation, $\mathrm{g}$ defines a transformation which rotates the specimen coordinate frame into the local crystal coordinate frame. $\Delta \mathrm{g}$ is the misorientation between neighboring crystallites where $\Delta \mathrm{g}$ rotates a grain with orientation $\mathrm{g}$ into the neighboring grain with orientation $\mathrm{g}^{\prime}$. That is

$$
\mathrm{g}^{\prime}=\Delta \mathrm{g} \cdot \mathrm{g}
$$

For the presentation of the stereological analysis we neglect dependence on lattice orientations as the $\Delta \mathrm{g}$ or $\mathrm{g}, \mathrm{g}^{\prime}$ dependence can be added later.

Consider a cylinder centered about a test line of direction $\mathbf{t}$. Let the cylinder have length $\mathrm{L}$, and perpendicular area $\delta \mathrm{A}$. Suppose that $\mathrm{S}_{\mathrm{V}}(\mathbf{n}) \mathrm{d} \mathbf{n}$ is the expected surface area per unit volume of interface with normal in the range $\mathrm{d} \mathbf{n}$ about $\mathbf{n}$. In the limit as $\delta \mathrm{A}$ goes to zero, the expected number of intersections of the test line, $\mathrm{P}(\mathbf{t})$, with interfaces in this range is

$$
\mathrm{P}(\mathbf{t})=\frac{\mathrm{S}_{\mathrm{V}}(\mathbf{n}) \mathrm{dn} L \delta \mathrm{A}}{\delta \mathrm{A} /|\mathbf{t} \cdot \mathbf{n}|} .
$$

Dividing by the length of the cylinder to get intersections per unit length and integrating the right hand side of equation (2) over the range of $\mathbf{n}, \mathrm{S}^{2}$ which covers the surface of the unit sphere, gives 


$$
\mathrm{P}_{\mathrm{L}}(\mathbf{t})=\frac{1}{2} \int_{\mathbf{n} \in \mathrm{S}^{2}} \mathrm{~S}_{\mathrm{V}}(\mathbf{n})|\mathbf{t} \cdot \mathbf{n}| \mathrm{d} \mathbf{n}
$$

If lattice misorientation or individual lattice orientations are included in the analysis, equation (3) becomes

$$
\mathrm{P}_{\mathrm{L}}(\Delta \mathrm{g} \mid \mathbf{t})=\frac{1}{2} \int_{\mathbf{n} \in \mathrm{S}^{2}} \mathrm{~S}_{\mathrm{V}}(\mathbf{n}, \Delta \mathrm{g})|\mathbf{t} \cdot \mathbf{n}| \mathrm{d} \mathbf{n}
$$

or

$$
\mathrm{P}_{\mathrm{L}}\left(\mathrm{g}, \mathrm{g}^{\prime} \mid \mathbf{t}\right)=\int_{\mathbf{n} \in \mathrm{S}^{2}} \mathrm{~S}_{\mathrm{V}}\left(\mathrm{g}, \mathbf{n}, \mathrm{g}^{\prime}\right)|\mathbf{t} \cdot \mathbf{n}| \mathrm{d} \mathbf{n}
$$

respectively. The factor of one-half in front of the integral is lost when a boundary with normal, $\mathbf{n}$, pointing from a grain with orientation $g$ to a grain with orientation $\mathrm{g}^{\prime}$, is considered to be different than a boundary with orientations $g$ and $g^{\prime}$ switched.

Both of the functions $\mathrm{P}_{\mathrm{L}}(\mathbf{t})$ and $\mathrm{S}_{\mathrm{V}}(\mathbf{n})$ can be represented by a series of orthogonal basis functions. We have

$$
\mathrm{S}_{\mathrm{V}}(\mathbf{n})=\sum_{\mathrm{r}=0}^{\infty} \sum_{\mathrm{t}=-2 \mathrm{r}}^{2 \mathrm{r}} \mathrm{S}_{2 \mathrm{r}}^{\mathrm{t}} \mathrm{K}_{2 \mathrm{r}}^{\mathrm{t}}(\mathbf{n})
$$

and

$$
\mathrm{P}_{\mathrm{L}}(\mathbf{t})=\sum_{\mathrm{r}=0}^{\infty} \sum_{\mathrm{t}=-2 \mathrm{r}}^{2 \mathrm{r}} \mathrm{S}_{2 \mathrm{r}}^{\prime \mathrm{t}} \mathrm{K}_{2 \mathrm{r}}^{\mathrm{t}}(\mathbf{t})
$$

where $K_{2 r}^{t}(\mathbf{n})$ are the surface spherical harmonic functions [14] and $S_{2 r}^{t}$ and $S_{2 r}^{\prime t}$ are constant coefficients defining the corresponding functions. Only even $r$ terms appear in 
the series expansions given in equations (6) and (7) because $\mathrm{S}_{\mathrm{V}}(\mathbf{n})$ and $\mathrm{P}_{\mathrm{L}}(\mathbf{t})$ are even functions which exhibit non-sidedness. That is to say, $\mathrm{S}_{\mathrm{V}}(\mathbf{n})=\mathrm{S}_{\mathrm{V}}(-\mathbf{n})$ and $\mathrm{P}_{\mathrm{L}}(\mathbf{t})=\mathrm{P}_{\mathrm{L}}(-\mathbf{t})$. The expression $|\mathbf{t} \cdot \mathbf{n}|_{\text {is simply }}|\cos \alpha|_{\text {where } \alpha}$ is the angle between $\mathbf{n}$ and $\mathbf{t}$, and can also be expanded in a series of Legendre's polynomials.

$$
|\cos \alpha|=\sum_{\mathrm{r}=0}^{\infty} \mathrm{A}_{2 \mathrm{r}} \mathrm{P}_{2 \mathrm{r}}(\cos \alpha)
$$

where $\mathrm{P}_{2 \mathrm{r}}(\cos \alpha)$ are Legendre's polynomials and $\mathrm{A}_{2 \mathrm{r}}$ are constant coefficients given by $\mathrm{A}_{0}=1 / 2, \mathrm{~A}_{2}=5 / 8$, and

$$
A_{2 r}=(-1)^{r+1}(4 r+1) \frac{1 \cdot 3 \cdot 5 \ldots(2 r-3)}{2 \cdot 4 \cdot 6 \ldots(2 r+2)}
$$

for $r \geq 2$. Combining equations (3), (6), and (8) obtains

$$
\mathrm{P}_{\mathrm{L}}(\mathbf{t})=\frac{1}{2} \int_{\mathbf{n} \in \mathrm{S}^{2}}^{\infty} \sum_{\mathrm{r}=0}^{\infty} \sum_{\mathrm{t}=-2 \mathrm{r}}^{2 \mathrm{r}} \mathrm{S}_{2 \mathrm{r}}^{\mathrm{t}} \mathrm{K}_{2 \mathrm{r}}^{\mathrm{t}}(\mathbf{n}) \sum_{\mathrm{r}^{\prime}=0}^{\infty} \mathrm{A}_{2 \mathrm{r}^{\prime}} \mathrm{P}_{2 \mathrm{r}^{\prime}}(\cos \alpha) \mathrm{dn}
$$

The solution to this equation is found by defining new harmonics

$$
\mathrm{V}_{2 \mathrm{r}}(\mathbf{n})=\sum_{\mathrm{t}=-2 \mathrm{r}}^{2 \mathrm{r}} \mathrm{S}_{2 \mathrm{r}}^{\mathrm{t}} \mathrm{K}_{2 \mathrm{r}}^{\mathrm{t}}(\mathbf{n})
$$

and substituting them back into equation (10) to obtain

$$
\mathrm{P}_{\mathrm{L}}(\mathbf{t})=\frac{1}{2} \int_{\mathbf{n} \in \mathrm{S}^{2}}^{\infty} \sum_{\mathrm{r}=0}^{\infty} \mathrm{V}_{2 \mathrm{r}}(\mathbf{n}) \sum_{\mathrm{r}^{\prime}=0}^{\infty} \mathrm{A}_{2 \mathrm{r}^{\prime}} \mathrm{P}_{2 \mathrm{r}^{\prime}}(\cos \alpha) \mathrm{d} \mathbf{n}=\sum_{\mathrm{r}=0}^{\infty} \sum_{\mathrm{r}^{\prime}=0}^{\infty} \frac{2 \pi}{4 \mathrm{r}+1} \mathrm{~A}_{2 \mathrm{r}^{\prime}} \mathrm{V}_{2 \mathrm{r}}(\mathbf{t}) \delta_{\mathrm{rr}}
$$


where $\delta_{\text {rr' }}$ is the Kronecker delta (cf. [14] for this solution). From equations (7) and (12) we have

$$
\mathrm{P}_{\mathrm{L}}(\mathbf{t})=\sum_{\mathrm{r}=0}^{\infty} \sum_{\mathrm{t}=-2 \mathrm{r}}^{2 \mathrm{r}} \mathrm{S}_{2 \mathrm{r}}^{\prime \mathrm{t}} \mathrm{K}_{2 \mathrm{r}}^{\mathrm{t}}(\mathbf{t})=\sum_{\mathrm{r}=0}^{\infty} \frac{2 \pi}{4 \mathrm{r}+1} \mathrm{~A}_{2 \mathrm{r}} \sum_{\mathrm{t}=-2 \mathrm{r}}^{2 \mathrm{r}} \mathrm{S}_{2 \mathrm{r}}^{\mathrm{t}} \mathrm{K}_{2 \mathrm{r}}^{\mathrm{t}}(\mathbf{t})
$$

term by term comparison of this equation requires that

$$
\mathrm{S}_{2 \mathrm{r}}^{\mathrm{t}}=\mathrm{S}_{2 \mathrm{r}}^{\mathrm{t}} \frac{4 \mathrm{r}+1}{2 \pi} \frac{1}{\mathrm{~A}_{2 \mathrm{r}}}
$$

The $S_{2 r}^{\prime t}$ coefficients are found from the measured function $P_{L}(t)$ and the coefficients defining $\mathrm{S}_{\mathrm{V}}(\mathbf{n})$ are given by expression (13). The difference between the coefficients defining the measured and desired functions is merely a set of constant terms. This remarkably simple equation is an exact analytical solution giving coefficients defining a three-dimensional function per unit volume as obtained from two-dimensional information. The method used in previous IDF analyses [1] requires solving a complicated set of equations to determine the coefficients for the desired function.

If lattice misorientation dependence is incorporated, equations (6) and (7) become

$$
\begin{aligned}
& \mathrm{S}_{\mathrm{V}}(\mathbf{n}, \Delta \mathrm{g})=\sum_{\mathrm{r}=0}^{\infty} \sum_{\mathrm{t}=-2 \mathrm{r}}^{2 \mathrm{r}} \sum_{l=0}^{\infty} \sum_{\mu=1}^{\mathrm{M}(l)} \sum_{v=0}^{\mathrm{M}(l)} l \mu{ }_{v} \mathrm{~S}_{2 \mathrm{r}}^{\mathrm{t}} \mathrm{K}_{2 \mathrm{r}}^{\mathrm{t}}(\mathbf{n}):_{\mathrm{T}}^{\mu \nu}(\Delta \mathrm{g}) \\
& \mathrm{P}_{\mathrm{L}}(\Delta \mathrm{g} \mid \mathbf{t})=\sum_{\mathrm{r}=0}^{\infty} \sum_{\mathrm{t}=-2 \mathrm{r}}^{2 \mathrm{r}} \sum_{l=0}^{\infty} \sum_{\mu=1}^{\mathrm{M}(l)} \sum_{v=0}^{\mathrm{M}(l)} l \mu{ }_{\nu} \mathrm{S}_{2 \mathrm{r}} \mathrm{K}_{2 \mathrm{r}}^{\mathrm{t}}(\mathbf{t}) \dot{\mathrm{T}}_{l}^{\mu \nu}(\Delta \mathrm{g})
\end{aligned}
$$

where $\dot{\mathrm{T}}_{l}^{\mu \nu}(\Delta \mathrm{g})$ are the symmetric generalized spherical harmonics with cubic-cubic symmetry and $\mathrm{M}(l)$ is the maximum value of the indices $\mu$ and $v$ [15]. Including individual lattice orientations equations (6) and (7) become

$$
\mathrm{S}_{\mathrm{V}}\left(\mathrm{g}, \mathbf{n}, \mathrm{g}^{\prime}\right)=\sum_{\mathrm{r}=0}^{\infty} \sum_{\mathrm{t}=-2 \mathrm{r}}^{2 \mathrm{r}} \sum_{l=0}^{\infty} \sum_{\mu=1}^{\mathrm{M}(\mathrm{l})} \sum_{\mathrm{n}=-l}^{l} \sum_{l^{\prime}=0}^{\infty} \sum_{\mu^{\prime}=1}^{\mathrm{M}\left(l^{\prime}\right)} \sum_{\mathrm{n}^{\prime}=-l}^{l} l_{l \mu \mathrm{n}}^{l^{\prime} \mu^{\prime} \mathrm{n}^{\prime}} \mathrm{S}_{2 \mathrm{r}}^{\mathrm{t}} \mathrm{K}_{2 \mathrm{r}}^{\mathrm{t}}(\mathbf{n}) \mathrm{T}_{l}^{\mu \mathrm{n}}(\mathrm{g}) \mathrm{T}_{l^{\prime}}^{\mu^{\prime} \mathrm{n}^{\prime}}\left(\mathrm{g}^{\prime}\right)
$$




$$
\mathrm{P}_{\mathrm{L}}\left(\mathrm{g}, \mathrm{g}^{\prime} \mid \mathbf{t}\right)=\sum_{\mathrm{r}=0}^{\infty} \sum_{\mathrm{t}=-2 \mathrm{r}}^{2 \mathrm{r}} \sum_{l=0}^{\infty} \sum_{\mu=1}^{\mathrm{M}(\mathrm{l})} \sum_{\mathrm{n}=-l}^{l} \sum_{l^{\prime}=0}^{\infty} \sum_{\mu^{\prime}=1}^{\mathrm{M}\left(l^{\prime}\right)} \sum_{\mathrm{n}^{\prime}=-l^{\prime}}^{l^{\prime}} l_{l \mu \mathrm{n}} \mathrm{l}^{\prime} \mu^{\prime} \mathrm{n}^{\prime} \mathrm{S}_{2 \mathrm{r}}^{\prime} \mathrm{K}_{2 \mathrm{r}}^{\mathrm{t}}(\mathbf{t}) \quad \mathrm{T}_{l}^{\mu \mathrm{n}}(\mathrm{g}) \mathrm{T}_{l^{\prime}}^{\mu^{\prime} \mathrm{n}^{\prime}}\left(\mathrm{g}^{\prime}\right)
$$

respectively. The $\mathrm{T}_{l}^{\mu \mathrm{n}}(\mathrm{g})$ functions are also symmetric generalized spherical harmonics as given by Bunge [15]. The dots signify cubic crystal symmetry (no particular sample symmetry). The function $\mathrm{S}_{\mathrm{V}}\left(\mathrm{g}, \mathbf{n}, \mathrm{g}^{\prime}\right)$ necessarily exhibits the following property

$$
\mathrm{S}_{\mathrm{V}}\left(\mathrm{g}, \mathbf{n}, \mathrm{g}^{\prime}\right)=\mathrm{S}_{\mathrm{V}}\left(\mathrm{g}^{\prime},-\mathbf{n}, \mathrm{g}\right)
$$

This is not the non-sidedness condition necessary to force $\mathrm{S}_{\mathrm{V}}\left(\mathrm{g}, \mathbf{n}, \mathrm{g}^{\prime}\right)$ to be an even function in $\mathbf{n}$. Careful examination of equation (12), in conjunction with equation (8), reveals that Hilliard's stereological method cannot obtain odd order coefficients in the series representation of $\mathrm{S}_{\mathrm{V}}\left(\mathrm{g}, \mathrm{n}, \mathrm{g}^{\prime}\right)$. This stereological constraint is equivalent to imposing a non-sidedness condition; namely

$$
\mathrm{S}_{\mathrm{V}}\left(\mathrm{g}, \mathbf{n}, \mathrm{g}^{\prime}\right)=\mathrm{S}_{\mathrm{V}}\left(\mathrm{g},-\mathbf{n}, \mathrm{g}^{\prime}\right)
$$

The relationship between the coefficients defining the $\mathrm{P}_{\mathrm{L}}$ and $\mathrm{S}_{\mathrm{V}}$ functions remains unchanged for the functions given in equations (15) and (16) and also equations (17) and (18), that is

$$
\begin{gathered}
l \mu v S_{2 \mathrm{r}}^{\mathrm{t}}={ }_{l \mu \nu} \mathrm{S}_{2 \mathrm{r}}^{\prime \mathrm{t}} \frac{4 \mathrm{r}+1}{2 \pi} \frac{1}{\mathrm{~A}_{2 \mathrm{r}}} \\
{ }_{l \mu \mathrm{n}}^{l^{\prime} \mu^{\prime} \mathrm{n}^{\prime}} \mathrm{S}_{2 \mathrm{r}}^{\mathrm{t}}={ }_{l \mu \mathrm{n}}^{l^{\prime} \mu^{\prime} \mathrm{n}^{\prime}} \mathrm{S}_{2 \mathrm{r}}^{\prime \mathrm{t}} \frac{4 \mathrm{r}+1}{2 \pi} \frac{1}{\mathrm{~A}_{2 \mathrm{r}}} .
\end{gathered}
$$

\subsection{Using $S_{V}$ to Calculate the IDF}

The IDF is defined as the damaged surface area per unit surface of crystallite interface, $\mathrm{S}_{\mathrm{S}}^{\mathrm{D}}$ (the superscript $\mathrm{D}$ denotes damaged). The maximum value of the IDF is 1 for boundaries which are completely separated and 0 for interfaces on which no damage is observed. The analysis in section 2.1 enables measurement of the surface area per unit volume of a given type of grain boundary. A similar analysis yields the damaged surface area of crystallite interface per unit volume. When scanning along a line of direction $\mathbf{t}$, if only those grain boundaries are counted on which damage is observed at the point of 
intersection with the scan line, we obtain the damaged intersections per unit length of scan line, $\mathrm{P}_{\mathrm{L}}^{\mathrm{D}}(\mathbf{t})$. With this function equation (3) becomes

$$
\mathrm{P}_{\mathrm{L}}^{\mathrm{D}}(\mathbf{t})=\frac{1}{2} \int_{\mathbf{n} \in \mathrm{S}^{2}} \mathrm{~S}_{\mathrm{V}}^{\mathrm{D}}(\mathbf{n})|\mathbf{t} \cdot \mathbf{n}| \mathrm{d} \mathbf{n}
$$

where $\mathrm{S}_{\mathrm{V}}^{\mathrm{D}}(\mathbf{n})$ is the damaged surface area per unit volume. The solution of $\mathrm{S}_{\mathrm{V}}^{\mathrm{D}}(\mathbf{n})$ is identical to that described in section 2.1. An IDF can now be calculated directly:

$$
\mathrm{S}_{\mathrm{S}}^{\mathrm{D}}(\mathbf{n})=\frac{\mathrm{S}_{\mathrm{V}}^{\mathrm{D}}(\mathbf{n})}{\mathrm{S}_{\mathrm{V}}(\mathbf{n})}
$$

Again, functional dependence on crystallite lattice orientation or misorientation may be included as required.

\section{EXPERIMENTAL DETAILS}

Half-hard oxygen free electronic (OFE) alloy 101 copper plate $(99.99 \%$ pure) with a thickness of $1.27 \mathrm{~cm}$ was machined into cylindrical tensile specimens with a gage section diameter of $6.35 \mathrm{~mm}$. The axis of each specimen was aligned with the rolling direction in the plate. The specimens were annealed at $900^{\circ} \mathrm{C}$ in a vacuum of $10^{-6}$ torr for two hours and subsequently furnace cooled. The resulting equiaxed grain size was $165 \mu \mathrm{m}$. Creep experiments in uniaxial-axial tension with a stress of $10 \mathrm{MPa}$ were performed using dead-weight loading. The specimens were crept at $540^{\circ} \mathrm{C}(.6 \mathrm{~T} \mathrm{~m})$ for 48 hours $(\approx$ $.6 \mathrm{t}_{\mathrm{r}}$, where $\mathrm{t}_{\mathrm{r}}$ is the time to rupture). After unloading, the specimens were again allowed to furnace cool. The axial strain measured from the creep tests was less than 2 percent.

To analyze and quantify the grain boundary damage, line scans were made through the gage sections of the crept specimens and the $\mathrm{P}_{\mathrm{L}}$ functions were measured. Eight plane sections, with normal orientations in the plane of the plate, were prepared. This enabled

uniformly covering the unit sphere with scan directions. Sectioning was performed using a spark cutter with care taken to minimize damage to the microstructure as the cuts were made. The depth of damage on the plane surfaces from use of the spark cutter is estimated at $1 \mu \mathrm{m}$. The cutting was followed by a slight electrochemical polish which 
removed all surface damage caused by the spark cutter and yet care was taken to not significantly effect the cavities observable on the plane section.

To measure the $\mathrm{P}_{\mathrm{L}}$ functions, each plane section described above was divided into small regions. From each of these regions a grain map was constructed by manually digitizing all grain boundaries within that region. This mapping was accomplished using a scanning electron microscope (SEM) equipped with special features which enabled the rapid determination of individual crystallite lattice orientations. The boundaries were defined by line segments in the section plane which separated crystallites of differing orientations. The damage on a boundary was defined by a similar set of line segments. Voids on the interfaces were defined as damage if they were apparent at a magnification of $1000 x$ on the SEM. The orientation of each individual crystallite was measured using the Back-scattered Kikuchi Diffraction (BKD) method [16,17] and a point within each grain corresponding to a given orientation was manually digitized. Line scans were made in sixteen previously determined directions across each section with a perpendicular distance of $100 \mu \mathrm{m}$ between parallel scan lines. From these scans, data files were generated which contained the scan direction and the crystallite orientation for each grain on each boundary intersected. The data set included 2100 individual lattice orientations measured with 7000 grain boundaries digitized. This resulted in approximately 70,000 grain boundary intersections counted in 114 unique scan directions.

\section{RESULTS AND DISCUSSION}

From the data set collected a number of analyses were possible. Several calculations were made in an attempt to describe the damage observed in the structure. The results of these calculations are described and discussed in the following sections.

\subsection{Damage as a Function of Interface Normal Orientation}

The first step taken to identify preferentially damaged boundaries was to calculate $\mathrm{S}_{\mathrm{S}}^{\mathrm{D}}(\mathbf{n})$, the area fraction of damaged interface as a function of grain boundary normal orientation. The interface normal is defined by the polar and azimuthal angles, $\alpha$ and $\beta$,

in the specimen coordinate frame as shown in Figure 1. The functions $\mathrm{S}_{\mathrm{V}}(\mathbf{n})$ and $\mathrm{S}_{\mathrm{V}}(\mathbf{n})$ were expanded in Fourier series as suggested by equation (6). The truncation order of the expansions was $2 r=4$. This value was selected to be as small as possible in order to speed the calculations, and yet still show the major features of the functions. A stereographic projection of $S_{S}^{D}(\mathbf{n})$ plotted over $\alpha$ and $\beta$ as defined by Figure 1 is shown in 
Figure 2. The damage is observed to be quite uniform over the space of $\mathbf{n}$ with the exception of boundaries which are nearly normal to the tensile axis. The fraction of damage on interfaces normal to the tensile axis is almost double that on boundaries with normal oriented off the tensile axis as seen in Figure 2. The maximum area fraction of damage as a function of interface normal is about 0.09 .

This result differs from the previously reported IDF where the damage occurred preferentially on boundaries oriented at $45^{\circ}$ with the tensile axis. This discrepancy is consistent with published findings that the strain rate is a determining factor as to the orientation of interfaces which are preferentially damaged [18].

In the previous study, damage occurred in specimens crept to a strain of 0.03 over two hours, whereas the specimens in the present study were crept for 48 hours resulting in an unmeasurable axial strain to a resolution of 0.02 . It is presumed that the higher strain rate increases the effect of grain boundary sliding, thereby increasing the propensity for damage on boundaries with a large component of shear stress [19].

\subsection{Damage as a Function of Misorientation Angle}

Damage was then investigated as a function of the least misorientation angle between adjacent crystallite lattices without regard for the axis of rotation. This analysis was done by counting all grain boundary segments making up the grain maps described in section 3 without consideration of their lengths. The damaged segments were then counted separately, again without considering the lengths of the damaged segments or the fraction of damage. Figures 3.a and 3.b show the number of total boundaries and damaged boundaries as functions of misorientation angle. The superimposed line gives the random distribution of cubic-cubic misorientations [20,21] normalized to the number of boundaries measured.

The large number of boundaries with misorientation angle near $60^{\circ}$, seen in Figure 3.a, is indicative of the presence of many twin boundaries in the structure. In fcc materials the twin boundary is described by a $60^{\circ}$ rotation about the [111] axis ( $\Sigma 3$ in CSL notation) $[22,23]$. The large number of twin boundaries in the structure is characteristic of annealed fcc materials with low stacking fault energies. Figure 3.b shows a large number of damaged boundaries with misorientation angle near $60^{\circ}$. We note that not all of these are twin boundaries. Damage was observed, however, on a number of grain boundaries exhibiting the twin misorientation, but always off the composition plane. This finding has been reported previously [18]. Figure 3.c shows the fraction of damaged boundaries as a function of misorientation angle. Note that only a small fraction of the $60^{\circ}$ boundaries are damaged. Grain boundaries with misorientation angle from 10 to 13 
degrees exhibit a surprisingly high fraction of damage. These boundaries may be considered small angle boundaries which have been reported to be relatively damage resistant [7]. The maximum damage fraction measured is 0.284 and occurs near a misorientation angle of $23^{\circ}$.

\subsection{Damage as a Function of Lattice Misorientation}

Euler's angles were used in defining the orientations of crystallites. Figure 4 describes the angles to rotate from the specimen coordinate frame, $\mathrm{K}_{\mathrm{S}}$, to the crystal coordinate frame, $K_{c}$. $g$ will be used to denote the set of Euler's angles, $\left(\varphi_{1}, \Phi, \varphi_{2}\right)$, defining a generic orientation. Euler's angles are also used to define the misorientation between adjoining crystallites as given in equation (1). The space of cubic-cubic misorientations can be reduced into an asymmetric subspace to speed calculations without loss of generality [24,25].

We have considered projections of the ISDF onto surfaces of constant $\mathbf{n}$ and $\Phi$. $\mathbf{n}$ was selected to be $n=\left(90^{\circ}, 0^{\circ}\right)$ to coincide with the maximum damage direction. Estimates of $\mathrm{S}_{\mathrm{V}}(\mathbf{n}, \Delta \mathrm{g})$ were obtained from equation (15) by truncating at $2 \mathrm{r}=4$ and $l=16$. The projections for a series of constant $\Phi$ values are shown in Figure 5. The large peak observed at $\varphi_{1}=45^{\circ}, \Phi=72^{\circ}, \varphi_{2}=45^{\circ}$ indicates the presence of a high fraction of twin boundaries ( $\Sigma 3$ occurs at $\left.\varphi_{1}=45^{\circ}, \Phi=70.52^{\circ}, \varphi_{2}=45^{\circ}\right)$ as previously discussed. Most features of the ISDF do not resemble the results previously obtained for annealed copper sheet [1], but correspond to that observed for type 304 stainless steel tubing, as reported by Zhao [26].

Figure 6 shows the function $\mathrm{S}_{\mathrm{V}}(90,0, \Delta \mathrm{g})$ which contains a peak at the twin position and also at the position of low angle boundaries. To better understand this result, compare with the IDF for $\mathbf{n}=(90,0)$ which is shown is Figure 7 . This function was calculated solely for those areas in $\mathrm{S}_{\mathrm{V}}(\Delta \mathrm{g})$ which were greater than five percent of the maximum peak in $\mathrm{S}_{\mathrm{V}}(\Delta \mathrm{g})$. This was done to avoid truncation errors of the series expansions. If $\mathrm{S}_{\mathrm{V}}(\Delta \mathrm{g})$ were extremely low for a given set of angles, $\mathrm{S}_{\mathrm{V}}^{\mathrm{D}}(\Delta \mathrm{g})$ would also approach zero at this point. Therefore, the quotient of the two functions, which defines the IDF, could have an artificially large value. The value of five percent of the maximum peak was chosen by trial and error and determined to be the lowest value for which peaks did not appear to be artifacts of the truncation. The maximum peak in the IDF appeared at Euler angles of $\varphi_{1}=10^{\circ}, \Phi=88^{\circ}, \varphi_{2}=10^{\circ}$, which has a misorientation angle of about $12^{\circ}$. This value corresponds to a peak in Figure 3.c. When mapped into the asymmetric subspace of cubic-cubic misorientations, the peak falls at approximately $\varphi_{1}=80^{\circ}$, $\Phi=89.5^{\circ}, \varphi_{2}=80^{\circ}$ which lies on the boundary of this region. 
In the previous IDF measurement [1] it was concluded that damage occurred preferentially on certain special boundaries with group multiplicity greater than 1 , because all of the peaks in the function fell on the boundary of the asymmetric subspace. (It is interesting to note that all of the CSL boundaries can also be mapped onto the boundary of this subspace [24].) In the present calculation it again appears that the majority of the peaks lie directly on the boundary of the asymmetric subspace. There are, however, secondary peaks which do not lie on the boundary. This leads one to believe that while several types of interfaces are damaged under the given experimental conditions, certain special types of grain boundaries with lattice misorientation lying on this mathematical boundary are more readily damaged. This result is strengthened by the fact that microstructure and experimental conditions differed between the two sets of experiments. Although interfaces of differing orientation to the principal stress axis exhibited a high occurrence of damage, boundaries with similar types of crystallite lattice misorientations were preferentially damaged.

\subsection{Damage as a Function of Individual Lattice Orientation}

The primary difficulty in calculating an IDF as a function of individual lattice orientation is in managing the large space of the domain of the function. With functional dependence on the grain boundary normal as well as upon two lattice orientations, the domain of the IDF lies in an eight dimensional space. When cubic crystal symmetry is considered, equation (17) is valid for the calculation of $S_{V}\left(g, n, g^{\prime}\right)$. To calculate this function at discrete points through the entire domain would be extremely computer intensive (and is presently unrealistic). The goal of the analysis is to determine the types of grain boundaries which are most likely to be damaged under the given experimental conditions. To accomplish this goal we project the domain of the IDF onto twodimensional surfaces and identify parameters which are correlated with a large number of damaged interfaces. The first projection considered is that described in section 4.1. With this result, the interface normal is fixed at $\mathbf{n}=(90,0)$ as before, which reduces the remaining domain to six dimensions. However, the asymmetric region of Euler space for cubic lattices is a large space extending from 0 to $2 \pi$ in $\varphi_{1}, 0$ to $\pi / 2$ in $\varphi_{2}$, and $\cos ^{-1}$ $(1 / \sqrt{ } 3) \leq \Phi \leq \pi / 2$ [14]. If discrete points of the IDF were calculated every $5^{\circ} \times 5^{\circ} \times 5^{\circ}$ in this region, there would be approximately 7000 individual points to be calculated. When the second orientation is included in the analysis, this number is squared and approaches 49 million.

To further reduce the space and avoid such large calculations, we integrate $S_{V}\left(g, n, g^{\prime}\right)$ over the space of $g^{\prime}$. There remains the function $\mathrm{S}_{\mathrm{V}}(\mathrm{g}, \mathbf{n})$ which considers the lattice 
orientation of only one of the grains composing the boundary. Having $\mathbf{n}$ fixed, this function can be represented in the asymmetric subspace of cubic orientations in Euler angle space. The equation defining $\mathrm{S}_{\mathrm{V}}(\mathrm{g}, \mathbf{n})$ becomes

$$
\mathrm{S}_{\mathrm{V}}(\mathrm{g}, \mathbf{n})=\sum_{\mathrm{r}=0}^{\infty} \sum_{\mathrm{t}=-2 \mathrm{r}}^{2 \mathrm{r}} \sum_{l=0}^{\infty} \sum_{\mu=1}^{\mathrm{M}(l)} \sum_{\mathrm{n}=-l}^{l}{ }_{l \mu \mathrm{n}}^{000} \mathrm{~S}_{2 \mathrm{r}}^{\mathrm{t}} \mathrm{K}_{2 \mathrm{r}}^{\mathrm{t}}(\mathbf{n}) \mathrm{T}_{l}^{\mu \mathrm{n}}(\mathrm{g})
$$

with a similar equation for the damaged surface area. In calculating this function, truncations were again made at $2 \mathrm{r}=4$ and $l=16$. Figures 8,9 , and 10 show $\mathrm{S}_{\mathrm{V}}(\mathrm{g}, 90,0)$, $\mathrm{S}_{\mathrm{V}}^{\mathrm{D}}(\mathrm{g}, 90,0)$, and $\mathrm{S}_{\mathrm{S}}^{\mathrm{D}}(\mathrm{g}, 90,0)$ respectively.

Note the heterogeneity in damage as demonstrated by these functions. A steep peak is observed at $\varphi_{1}=120^{\circ}, \Phi=80^{\circ}, \varphi_{2}=30^{\circ}$ in $\mathrm{S}_{\mathrm{V}}(\mathrm{g}, 90,0)$. If damage were homogeneous in this space the peak should be at the same position, and with the same relative intensity in the $\mathrm{S}_{\mathrm{V}}^{\mathrm{D}}(\mathrm{g}, 90,0)$ function. As seen in Figure 9, a small peak is observed at this set of parameters, but a much steeper peak is seen at $\varphi_{1}=40^{\circ}, \Phi=90^{\circ}, \varphi_{2}=50^{\circ}$, indicating heterogeneity in damage depending upon crystallite lattice orientation. This result indicates that it may be important to consider the orientations of individual grains in defining the boundaries which are preferentially damaged, and not merely their misorientation. The damaged surface area per unit surface was calculated for all areas of $\mathrm{S}_{\mathrm{V}}(\mathrm{g}, 90,0)$ which were greater than 10 percent of the maximum value. Figure 10 shows that the maximum fraction of damage is 0.486 which occurs at $\varphi_{1}=30^{\circ}, \Phi=90^{\circ}, \varphi_{2}=50^{\circ}$. This suggests that crystallites of the given orientation were easily damaged on interfaces normal to the tensile axis regardless of the orientation of the neighboring crystallite.

To calculate a portion of the IDF in eight dimensional space requires that we find values for the coefficients ${ }^{l} l \mu \mathrm{n}{ }^{\prime} \mathrm{S}^{\prime} \mathrm{S}_{2 \mathrm{r}}^{\mathrm{t}}$ as shown in equation (17). If this calculation were performed for truncation values similar to those used previously; that is $2 \mathrm{r}=4, l=16$, and $l^{\prime}=16$, there would be approximately 2.2 million complex coefficients required to define each function. Defining and updating the coefficients requires that two arrays of this size be stored either on disk or virtual memory. While this is certainly possible with current computing technology, the CPU time required for such a calculation is excessive considering that 70,000 measurements were used in determining the coefficients. To manage the calculation, truncations of $2 \mathrm{r}=4, l=8$, and $l^{\prime}=8$ were held. $\mathbf{n}$ was again kept constant, aligned with the tensile axis, and the lattice orientation of the first grain was fixed at $\varphi_{1}=30^{\circ}, \Phi=90^{\circ}, \varphi_{2}=50^{\circ}$, the maximum value obtained from $\mathrm{S}_{\mathrm{S}}^{\mathrm{D}}(\mathrm{g}, 90,0)$. Figures 11, 12 and 13 show the functions $S_{V}\left(30,90,50,90,0, g^{\prime}\right), S_{V}^{D}\left(30,90,50,90,0, g^{\prime}\right)$, 
and $\mathrm{S}_{\mathrm{S}}^{\mathrm{D}}\left(30,90,50,90,0, \mathrm{~g}^{\prime}\right)$ respectively plotted over the space of $\mathrm{g}^{\prime}$. Notice that Figures 11 and 12 are quite similar to Figures 8 and 9 with the exception that the peaks are broader due to the lower truncation of the series expansions. The plots are similar because all $\mathrm{g}^{\prime}$ orientations were included in the calculation of interface area as a function of a single lattice orientation.

The major peaks of the IDF in the space of $\mathrm{g}^{\prime}$, along with the corresponding misorientation values between $\mathrm{g}$ and $\mathrm{g}^{\prime}$ are recorded in Table 1 . The maximum damage fraction is 0.545 at $\varphi_{1}=140^{\circ}, \Phi=80^{\circ}, \varphi_{2}=50^{\circ}$. Note that the IDF has a value near 0.3 for a neighboring grain with the same orientation as the first. This is caused by the two major peaks of the function, which lie near the fixed orientation of $\varphi_{1}=30^{\circ}, \Phi=90^{\circ}, \varphi_{2}=50^{\circ}$, at misorientation angles of about 10 degrees. The two peaks are broad because of the eighth order truncation, since each contributes to the IDF at a misorientation of zero. Several such artifacts may be present in this calculation and as a result, only first order information is reliable. Note from Table 1 that the misorientations of the peaks found in the eight-dimensional IDF correspond to several of the peaks in the IDF as a function of lattice misorientation (Figure 7).

\section{SOME POSSIBLE DAMAGE MECHANISMS}

Identifying interfaces which are easily damaged under given experimental conditions enables a thorough investigation of the mechanisms which may cause the damage. Various researchers have concentrated on isolating damage mechanisms [27-33]. Fracture mechanism maps which show the suspected dominating mechanism as a function of stress and temperature have been constructed for a number of materials [27]. Ashby and his co-workers identify the primary mechanisms as volume diffusion (Nabarro-Herring creep [34,35]), surface diffusion (Coble creep [36]), and dislocation mechanisms which cause creep behavior to have a power law dependence. These maps are generally useful in predicting fracture life of a component but do not consider the heterogeneity of damage in the microstructure and are therefore used only as a first step in isolating mechanisms. Using the data available in this study, it becomes possible to investigate more precisely what occurs on interfaces which are preferentially damaged. In this section we discuss a number of mechanisms which may be responsible for damaging certain types of boundaries, and factors which contribute to damage heterogeneity. 
It has long been theorized that grain boundary voids can grow by diffusion of atoms away from the surface of a void or nucleus [37,38]. The growth of the voids is dependent upon the stress imposed on the boundary. Local stress gradients in a polycrystal are a function of several variables, one of which is the structure of crystallite interfaces. Grain boundaries on which high stresses are present may be more readily damaged by diffusion, grain boundary sliding, or by some other mechanism. It has been shown that boundaries which experience a large tensile hydrostatic component of stress are more easily damaged than those on which the hydrostatic pressure is negligible or compressive [31,37]. While several models exist to calculate the local stress gradient at a point in a polycrystal (cf. [39]), there is never enough available information on the microstructure of the material to find the stress gradient with high certainty.

Grain boundary energy may be another important factor in determining susceptibility to boundary damage. It has been suggested that boundaries classified in the CSL system as low $\Sigma$ boundaries are low energy boundaries and should be relatively damage resistant $[7,40]$. It seems reasonable that high energy boundaries, or those which are thermodynamically less stable, will be preferentially damaged. However, determining grain boundary energies involves more than knowing the CSL classification of the boundary. It has been concluded that grain boundaries which have the same grain boundary normal and also the same lattice misorientation are not necessarily identical electronically [41]. Therefore, boundaries of similar lattice misorientation may have differing grain boundary energies.

Dislocation interactions with crystallite interfaces may also be an important factor in the heterogeneity of damage in a polycrystal. Slip incompatibilities at an interface have been shown to be a cause of premature fracture in crept bicrystals [42,43]. If slip is not easily transferred across an interface, stress concentrations develop which may contribute to damage on the boundary. In section 4 it was found that some small angle boundaries were preferentially damaged. Since slip is easily transferred on these types of boundaries, slip incompatibility obviously did not contribute to the damage. Various slip transfer models [44-46] were compared with the measured damage functions in an attempt to explain damage heterogeneity. These comparisons failed to isolate any class of boundaries observed to be heavily damaged. This apparently suggests the importance of nonlocal effects.

Chemical differences of grain boundaries are another cause of damage heterogeneity [cf. 47]. However, the copper specimens used in this study were reasonably pure and were damaged in an inert environment. While this does not mean that the small chemical differences present on the boundaries did not contribute to damage heterogeneity, the 
differences were not observable in this analysis and must be neglected. Non-uniformly distributed grain boundary precipitates may act as nucleation sites for interface cavities, but precipitates were not observed in either the virgin or crept specimens.

\section{CONCLUSIONS}

The large number of grain boundaries examined in this study is believed to constitute the most complete description of damage heterogeneity to date. The results of previous measurements of the IDF [1] are significantly different than the results described in section four of this paper. This is not necessarily surprising since the IDF is dependent on material and experimental conditions; the microstructures, temperatures, stresses, and strain rates of the two sets of experiments differed significantly.

The results reported in section four show that the IDF is useful in identifying types of interfaces which are preferentially damaged. The IDF, with functional dependence on interface normal and lattice misorientation, demonstrates that grain boundary damage is a function of crystallite misorientation and that some small angle boundaries were readily damaged. As previously observed, special misorientations of group multiplicity greater than one were damaged to a higher degree than boundaries with misorientation lying within the asymmetric subspace. Examining the results of section 4.4 and, in particular, the function $\mathrm{S}_{\mathrm{S}}^{\mathrm{D}}(\mathrm{g}, 90,0)$, suggests that damage heterogeneity is additionally a function of the orientation of each individual crystallite composing an interface. This indicates that five degrees of freedom are inadequate in identifying damaged grain boundaries, and that damage mechanisms at the interface are dependent on the individual orientations of each crystallite. Hilliard's stereological method of determining the function $\mathrm{S}_{\mathrm{V}}\left(\mathrm{g}, \mathbf{n}, \mathrm{g}^{\prime}\right)$ demands that only even $r$ terms be considered in the series expansion, given by equation (17). This restriction inherently imposes the non-sidedness condition to this function. Calculating the function $S_{\mathrm{S}}^{\mathrm{D}}\left(\mathrm{g}, \mathbf{n}, \mathrm{g}^{\prime}\right)$ for discrete points through the entire domain is unrealistic because of the size of the space. From a series of two-dimensional projections through the enormous space of the eight-dimensional domain of this IDF, peaks in the function were found which were consistent with those observed as a function of lattice misorientation. However, the eighth-order truncation used to perform the calculations yielded only first order information. 


\section{ACKNOWLEDGEMENT}

The authors acknowledge the support of the Office of Basic Energy Sciences of the United States Department of Energy.

\section{REFERENCES}

1. B. L. Adams, J. Zhao and D. O’Hara, Acta metall. mater., 38, 953 (1990).

2. J. E. Hilliard, Trans. Am. Inst. Min. Engrs. 224, 1201 (1963).

3. T.G. Nieh and W.D. Nix, Acta metall., 28, 557 (1980).

4. S.E. Stanzl, A.S. Argon, and E.K. Tschegg, Acta metall., 31, 833, (1983).

5. L.C. Lim and R. Raj, Acta metall., 32, 1177 (1984).

6. I.W. Chen and A.S. Argon, Acta metall., 29, 1321, (1981).

7. J. Don and S. Majumdar, Acta metall., 34, 961 (1986).

8. T. Watanabe, J. de Physique, 49, C5-507 (1988).

9. T. Watanabe, H. Fujii, H. Oikawa, and K.I. Arai, Acta metall., 37, 941 (1989).

10. L.C. Lim and T. Watanabe, Acta metall. mater., 38, 2507 (1990).

11. B. L. Adams, Metall. Trans. 17A, 2199 (1986).

12. J. Zhao, J. S. Koontz and B. L. Adams, Metall. Trans. 19A, 1179 (1988).

13. B.L. Adams and D.P. Field, unpublished research.

14. E.W. Hobson, The Theory of Spherical and Ellipsoidal Harmonics, Chelsea Publishing Co., New York (1955).

15. H.J. Bunge, Texture Analysis in Materials Science, Butterworths, London (1982).

16. J. A. Venables and C. J. Harland, Phil. Mag., 27, 1193 (1973).

17. D. J. Dingley and K. Baba-Kishi, Scanning Electron Microscopy, II, 383 (1986).

18. A. Rukwied, Metall. Trans., 3, 3009 (1972).

19. R. W. Evans and B. Wilshire, Creep of Metals and Alloys, Pineridge Press, Swansea (1985).

20. J.K. Mackenzie, Biometrika, 45, 229 (1958).

21. D.C. Handscomb, Canad. J. Math., 10, 85 (1958).

22. W. Bollmann, Crystal Defects and Crystalline Interfaces, Springer-Verlag, New York (1970).

23. D.H. Warrington and P. Bufalini, Scripta Metall., 5, 771 (1971).

24. J. Zhao and B. L. Adams, Acta cryst., A44, 326 (1988).

25. B.L. Adams, J. Zhao and H Grimmer, Acta cryst., A46, 620 (1990).

26. J. Zhao, PhD dissertation, Brigham Young University, Provo, UT, (1988). 
27. M.F. Ashby, C. Gandhi, and D.M.R. Taplin, Acta Metall., 27, 699 (1979).

28. B. F. Dyson, Metal Sci., 10, 349 (1976).

29. B.F. Dyson, Rev. Phys. Appl., 23, 605 (1988).

30. J. R. Rice, Acta metall., 29, 675 (1981).

31. A. C. F. Cocks and M. F. Ashby, Prog. in Mat. Sci., 27, 189 (1982).

32. S. Takeuchi and A.S. Argon, J. Matls. Science, 11, 1542 (1976).

33. O.A. Ruano and O.D. Sherby, Rev. Phys. Appl., 23, 625 (1988).

34. F.R.N. Nabarro, Strength of Solids, Phys. Soc. of London (1948).

35. C. Herring, J. Appl. Phys., 21, 437 (1950).

36. R.L. Coble, J. Appl. Phys., 34, 1679 (1963).

37. D. Hull and D.E. Rimmer, Phil. Mag., 4, 673 (1959).

38. M.V. Speight and J.E. Harris, Metal Sci., 1, 83 (1967).

39. B.L. Adams, G.R. Canova and A. Molinari, Textures and Microstructures, 11, 57 (1989).

40. A.P. Sutton and R.W. Balluffi, Acta metall., 35, 2177 (1987).

41. M.A. Shtremel, Fiz. Met. Metalloved. (USSR), no. 5, pp. 15-21 (May, 1990).

42. R. Raj, Acta metall., 26, 341 (1978).

43. L.C. Lim and R. Raj, Acta metall., 33, 2205 (1985).

44. J.D. Livingston and B. Chalmers, Acta metall., 5, 322 (1957).

45. Z. Shen, R.H. Wagoner, and W.A.T. Clark, Acta metall., 36, 3231 (1988).

46. E. Werner and W. Prantl, Acta metall. mater., 38, 533 (1990).

47. S.P. Lynch, Materials Science Forum, 46, 1 (1989). 


\section{LIST OF FIGURES}

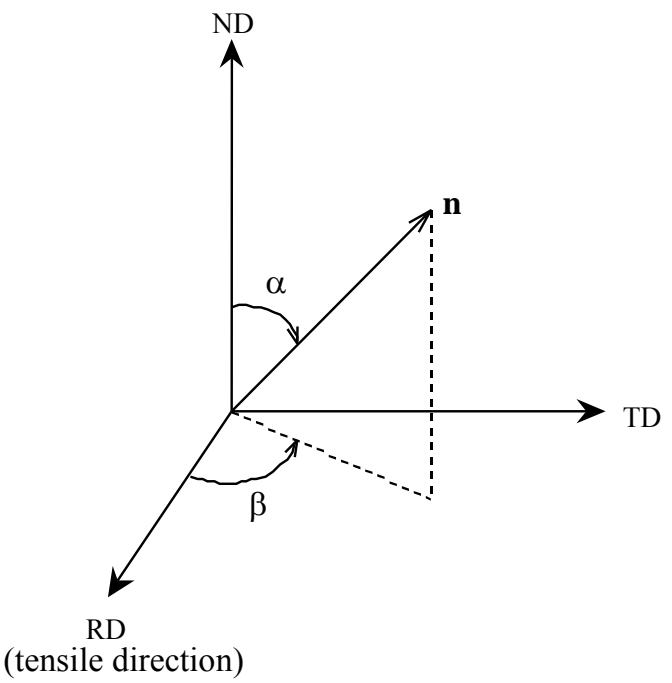

Figure 1 - Definition of the polar and azimuthal angles in the specimen coordinate frame given by the rolling (RD), transverse (TD), and normal (ND) directions of the sheet.

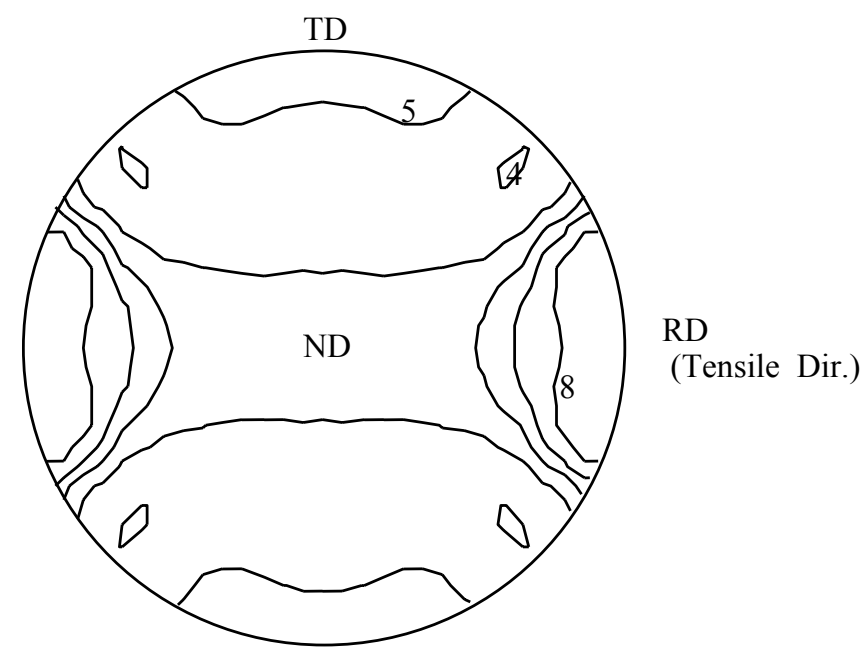

Figure 2 - Symmetrized $S_{S}^{D}(\mathbf{n})$ showing measured damage fraction as a function of interface normal orientation. Contour lines are at 4, 5, 6, 7 , and 8 percent damage. 

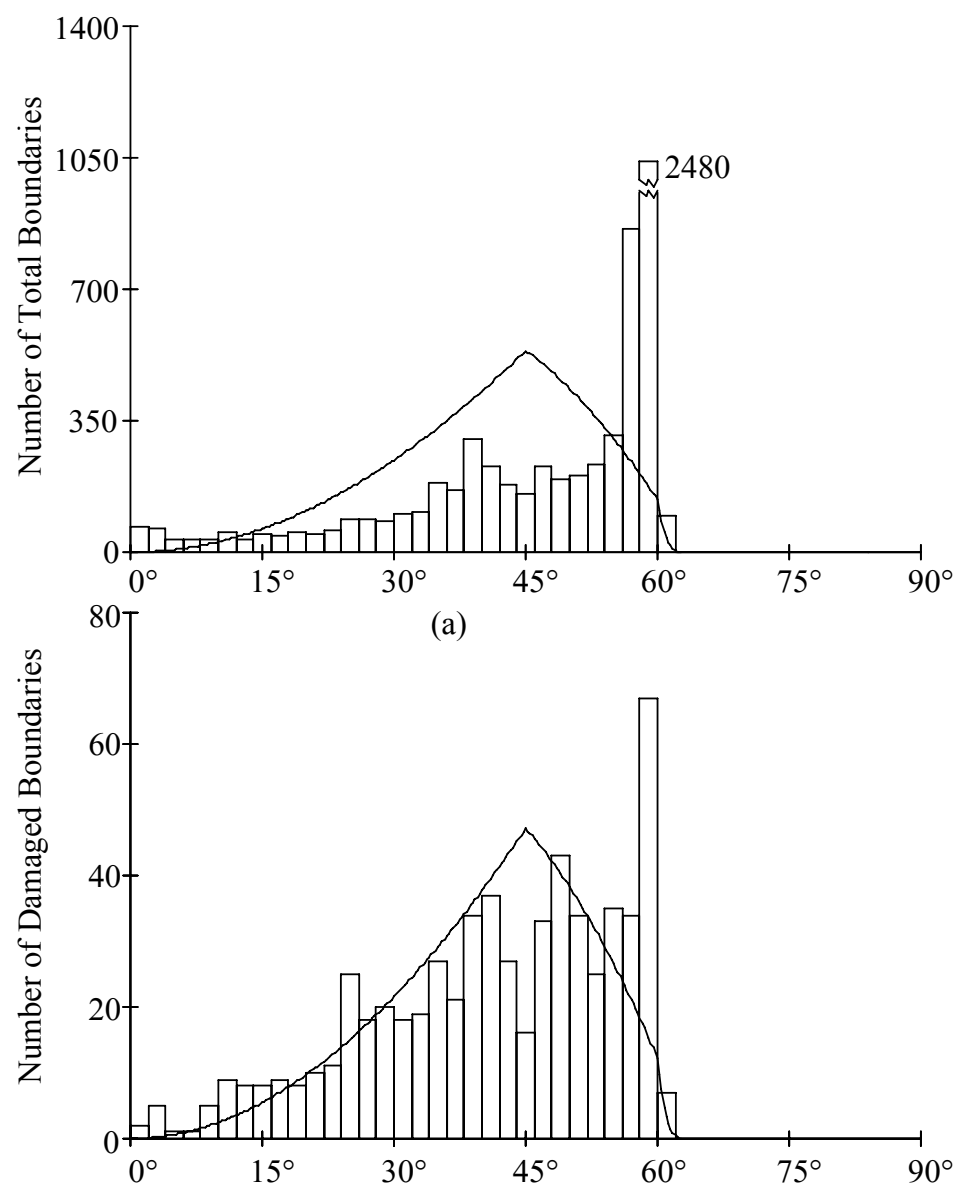

(b)

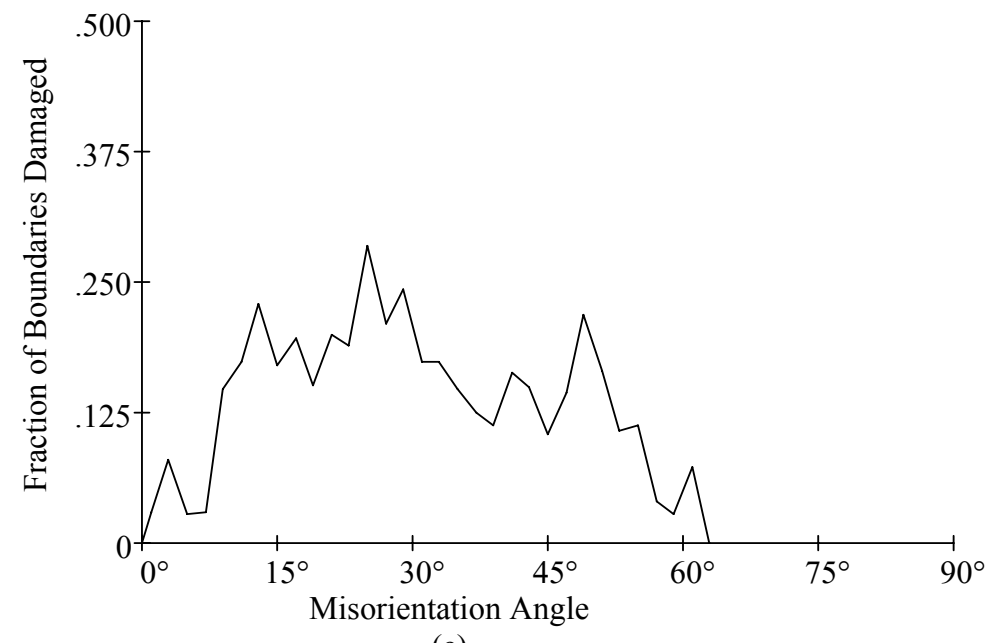

(c)

Figure 3 - (a) Total number, (b) number damaged, and (c) damaged fraction of boundaries categorized by minimum misorientation angle. Superimposed on (a) and (b) is the random distribution of misorientation angles. 


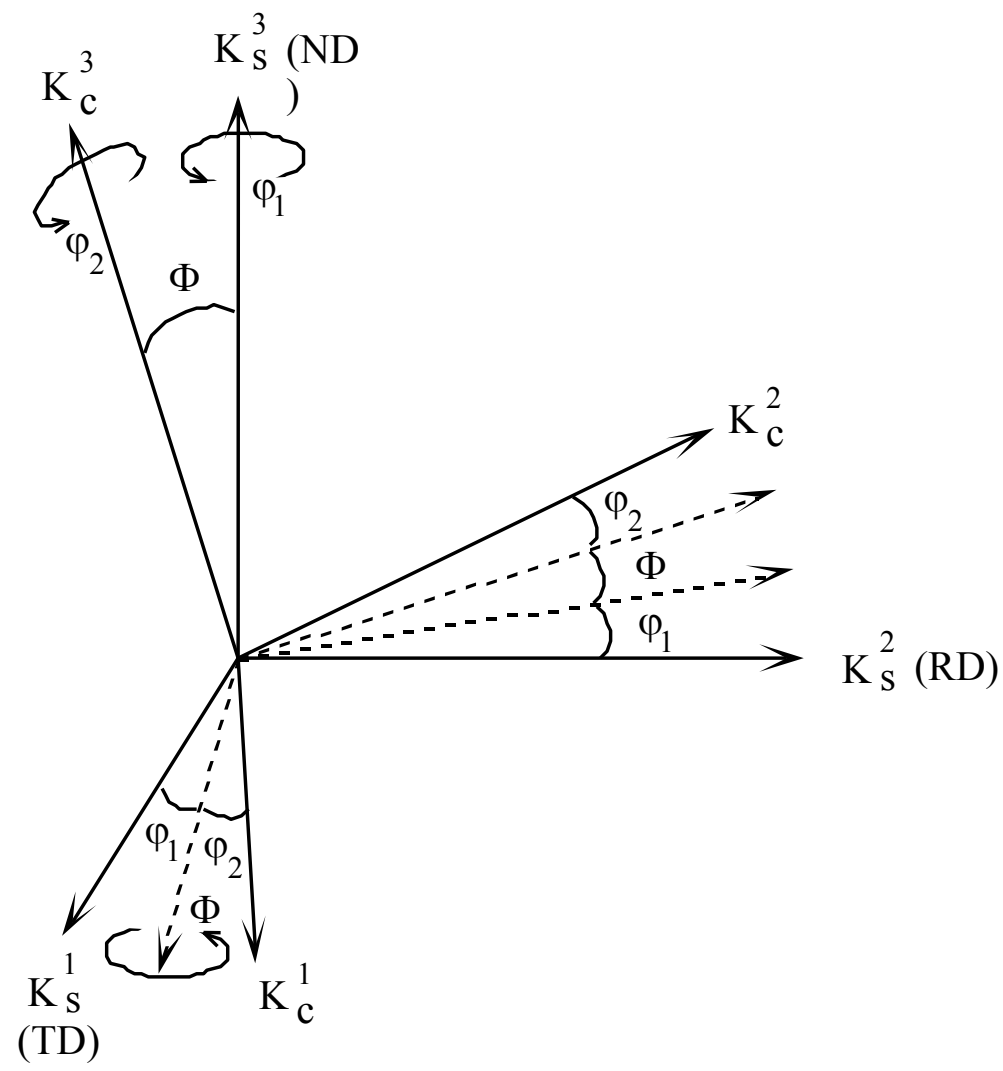

Figure 4 - Definition of Eulers angles defining a rotation from the specimen coordinate frame to the crystal coordinate frame. 

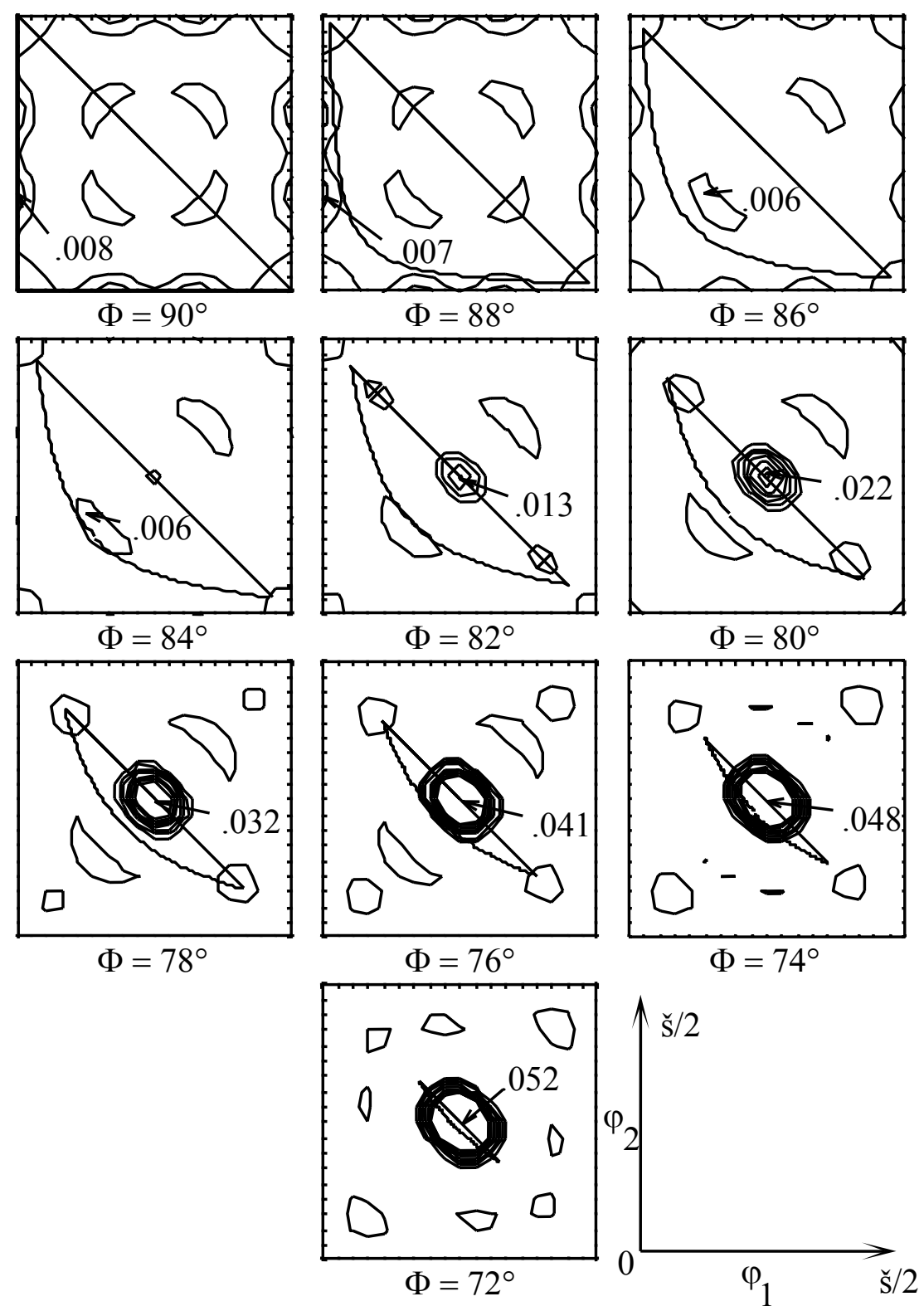

Figure 5 - $\mathrm{S}_{\mathrm{V}}(90,0, \Delta \mathrm{g})$, contour lines at equal intervals of $0.3 \times 10^{-3} / \mu \mathrm{m}$. Maximum peaks shown are $x 10 / \mu \mathrm{m}$. The superimposed region shows the asymmetric subspace of cubic-cubic misorientations. 


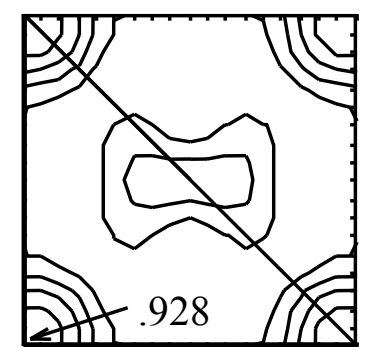

$\Phi=90^{\circ}$
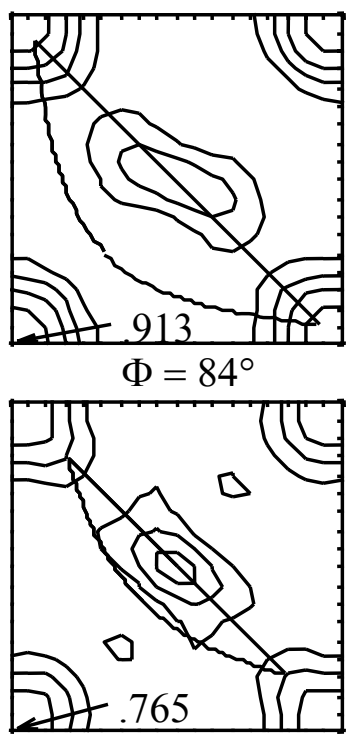

$\Phi=78^{\circ}$

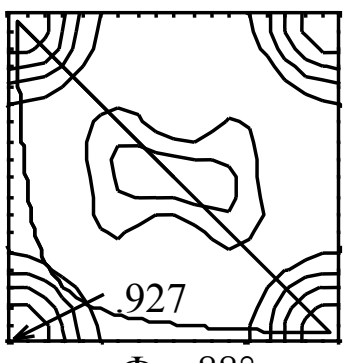

$\Phi=88^{\circ}$

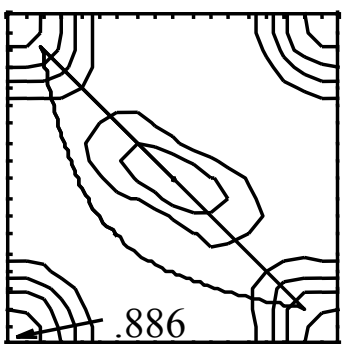

$\Phi=82^{\circ}$

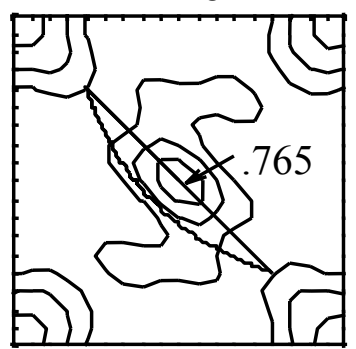

$\Phi=76^{\circ}$

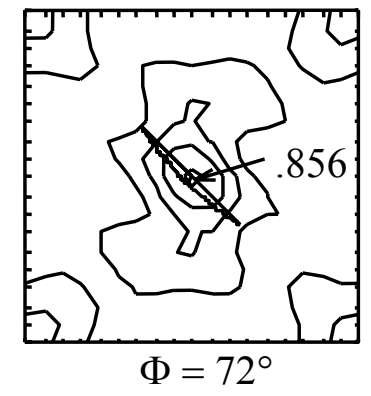

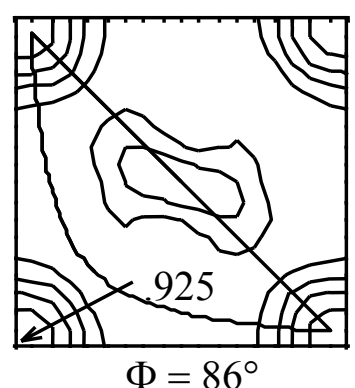

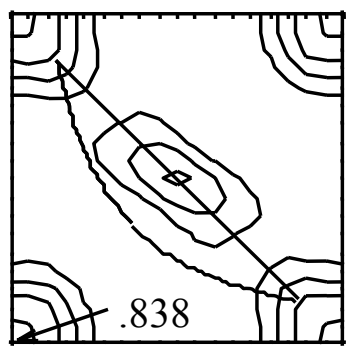

$\Phi=80^{\circ}$

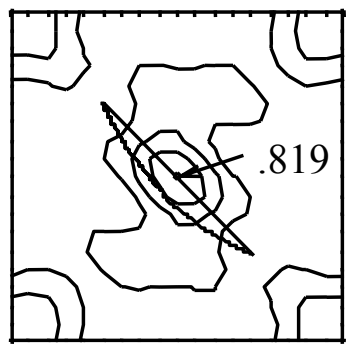

$\Phi=74^{\circ}$

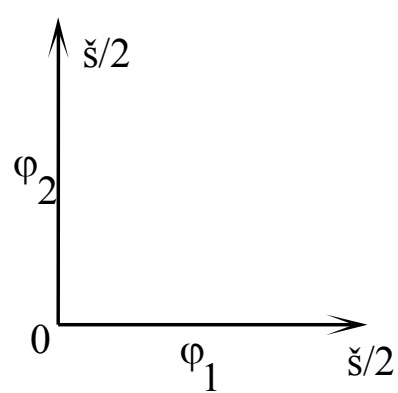

Figure 6 - $\mathrm{S}_{\mathrm{V}} \mathrm{D}(90,0, \Delta \mathrm{g})$, contour lines at equal intervals of $0.2 \times 10^{-4} / \mu \mathrm{m}$. Maximum peaks shown are $\times 10^{4} / \mu \mathrm{m}$. The superimposed region shows the asymmetric subspace of cubic-cubic misorientations. 


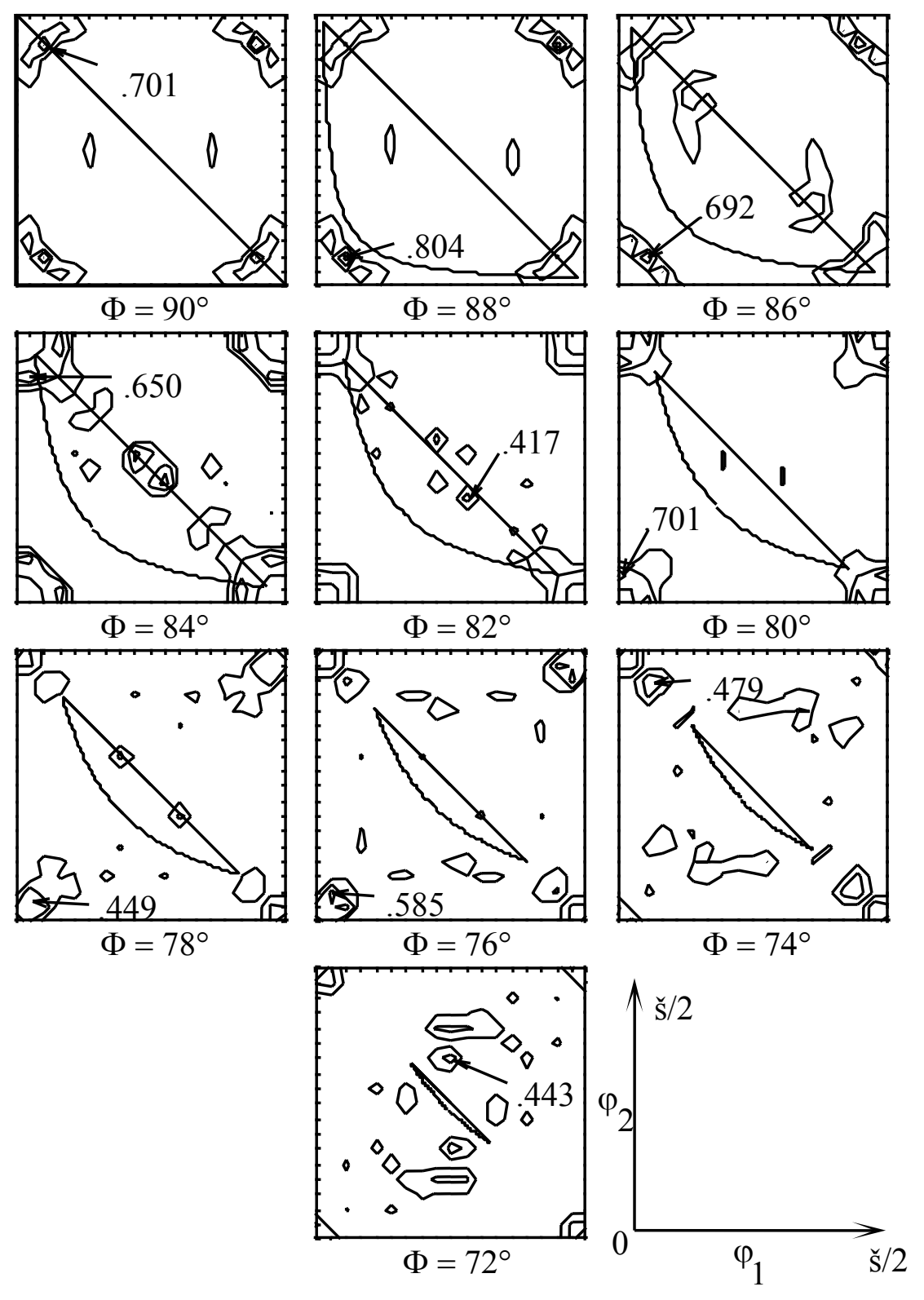

Figure $7-\mathrm{S}_{\mathrm{S}}^{\mathrm{D}}(90,0, \Delta \mathrm{g})$, contour lines at $0.1,0.3,0.5$, and 0.7. The superimposed region shows the asymmetric subspace of cubic-cubic misorientations. 

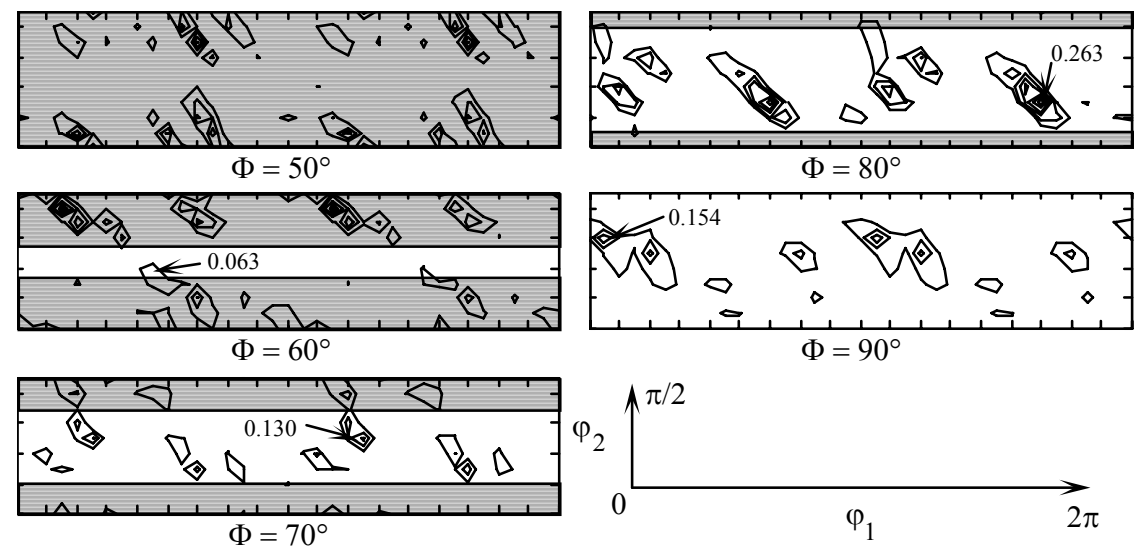

Figure $8-S_{V}(g, 90,0)$, contours are at equal intervals of $0.4 \times 10^{-3} / \mu \mathrm{m}$. Values for the peaks shown are $\mathrm{x} 10 / \mu \mathrm{m}$. The shaded portion of the plots is the region lying outside of the asymmetric domain of cubic orientations.

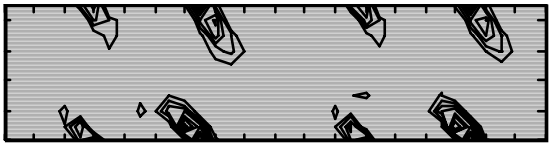

$\Phi=50^{\circ}$

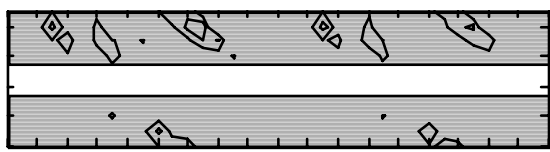

$$
\Phi=60^{\circ}
$$

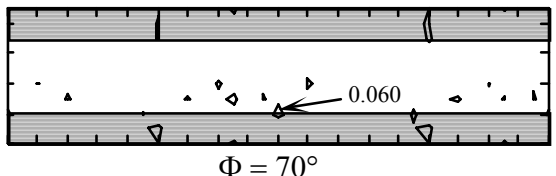

$\Phi=70^{\circ}$

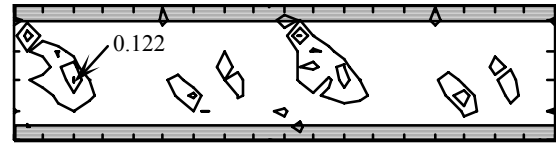

$\Phi=80^{\circ}$
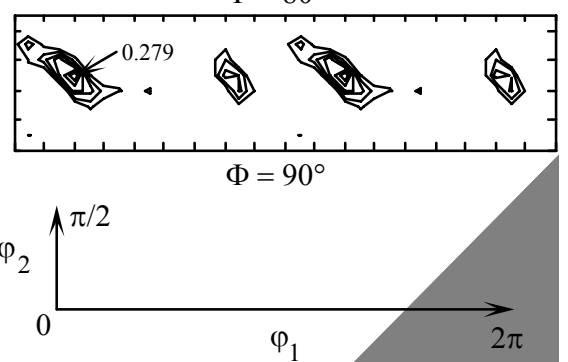

Figure $9-\mathrm{S}_{\mathrm{V}}^{\mathrm{D}}(\mathrm{g}, 90,0)$, contours are at equal intervals of $0.4 \times 10^{-4} / \mu \mathrm{m}$. Values for the peaks shown are $\mathrm{x} 10 \stackrel{\mathrm{R}}{\mathrm{mm}}$. The shaded portion of the plots is the region lying outside of the asymmetric domain of cubic orientations. 

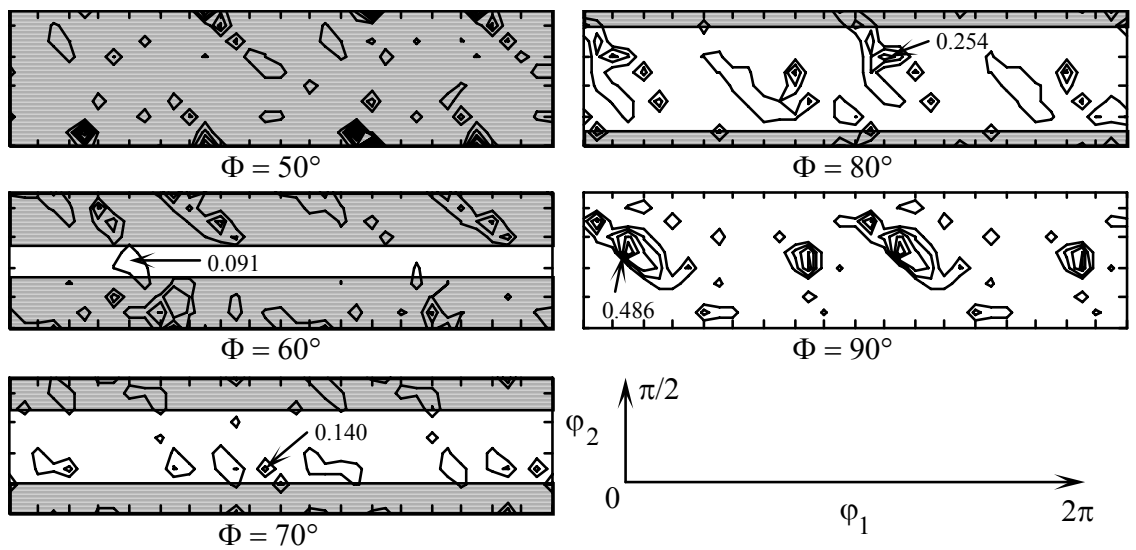

Figure $10-S_{S}^{D}(g, 90,0)$, contours are at equal intervals of 0.1 . The shaded portion of the plots is the region lying outside of the asymmetric domain of cubic orientations.
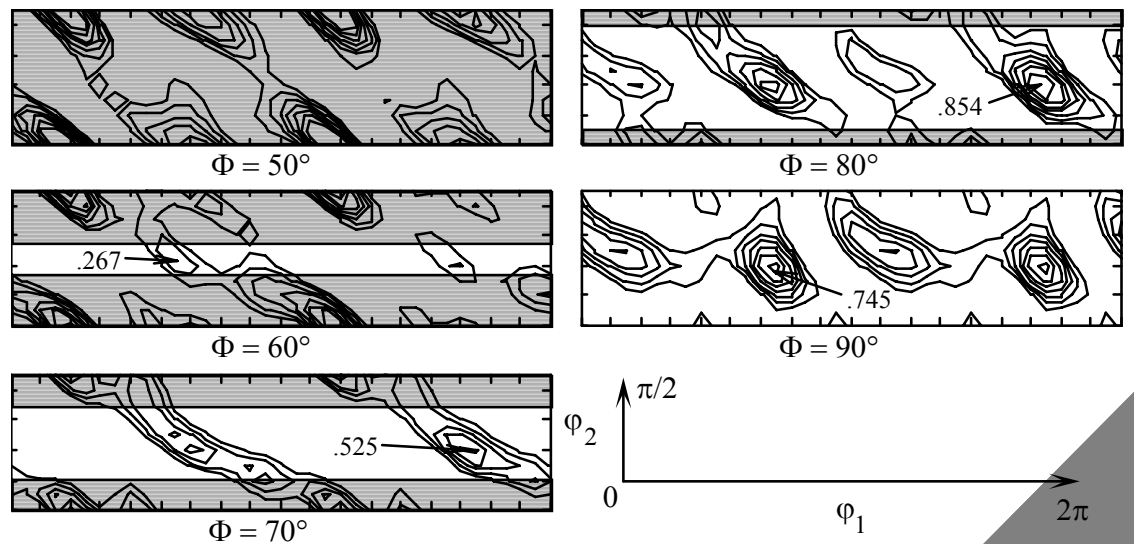

Figure $11-\mathrm{S}_{\mathrm{V}}\left(30,90,50,90,0, \mathrm{~g}^{\prime}\right)$, contours are at equal increments of $0.1 \mathrm{x} 10-7 / \mathrm{\mu m}$. Peaks are labelled at $\times 10 f_{\mu \mathrm{m}}$. The shaded portion of the plots is the region lying outside of the asymmetric domain of cubic orientations. 


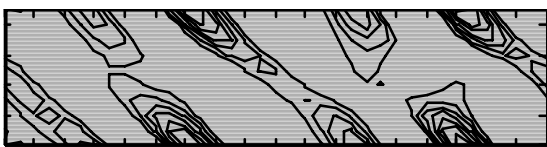

$\Phi=50^{\circ}$

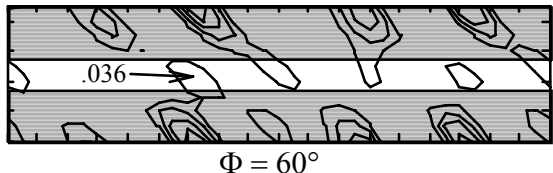

$\Phi=60^{\circ}$

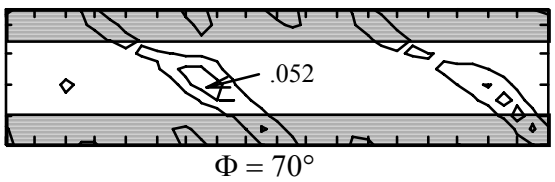

$\Phi=70^{\circ}$

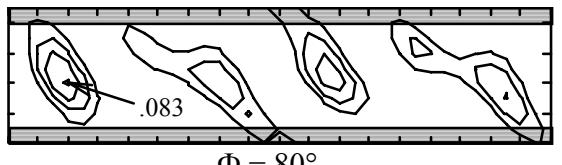

$\Phi=80^{\circ}$
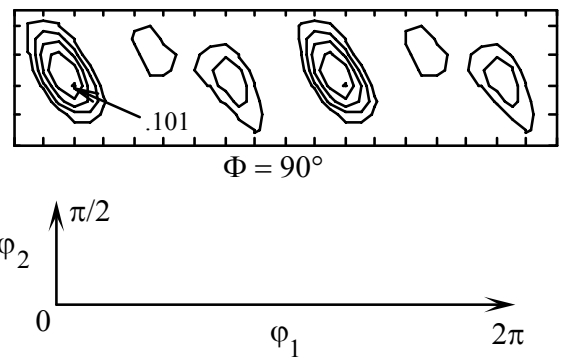

Figure $12-\mathrm{S}_{\mathrm{V}}^{\mathrm{D}}\left(30,90,50,90,0, \mathrm{~g}^{\prime}\right)$, contours are at equal increments of $0.2 \times 10-\not \mu \mathrm{m}$. Peaks are labelled at $\times 102 \mu \mathrm{m}$. The shaded portion of the plots is the region lying outside of the asymmetric domain of cubic orientations.
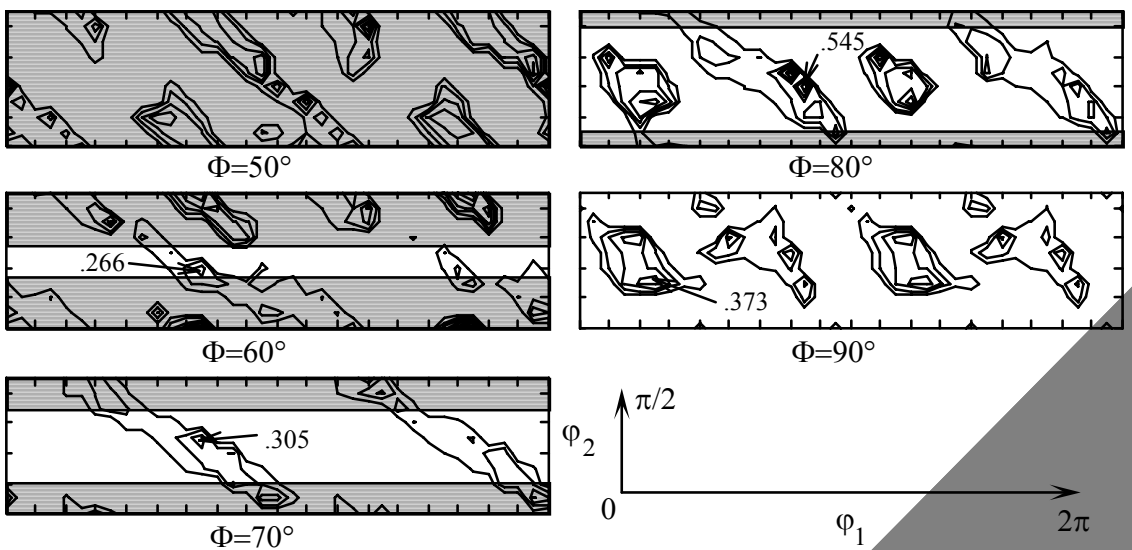

Figure $13-\mathrm{S}_{\mathrm{S}}^{\mathrm{D}}\left(30,90,50,90,0, \mathrm{~g}^{\prime}\right)$, contours begin at 0 and are at equal increments of 0.1 . The shaded portion of the plots is the region lying outside of the asymmetric domain of cubic orientations. 
Table 1 - Some Major Peaks in the Function $\mathrm{S}_{\mathrm{S}}^{\mathrm{D}}\left(\mathrm{g}, \mathbf{n}, \mathrm{g}^{\prime}\right)$, with $\mathbf{n}=90^{\circ}, 0^{\circ}$, and $\mathrm{g}=30^{\circ}, 90^{\circ}, 50^{\circ}$.

\begin{tabular}{|c|c|c|c|}
\hline $\begin{array}{l}\text { Euler Angles } \\
\text { of Adjoining } \\
\text { Grain }\left(\mathrm{g}^{\prime}\right) \\
\varphi_{1}^{\prime}, \Phi^{\prime}, \varphi_{2}^{\prime}\end{array}$ & $\begin{array}{l}\text { Calculated } \\
\text { Damage } \\
\text { Fraction }\end{array}$ & $\begin{array}{l}\text { Euler Angles } \\
\text { Defining } \\
\text { Misorientation }(\Delta \mathrm{g}) \\
\qquad \Delta \varphi_{1}, \Delta \Phi, \Delta \varphi_{2} \\
\end{array}$ & $\begin{array}{l}\text { Group } \\
\text { Multiplicity of } \\
\text { Misorientation }\end{array}$ \\
\hline 140,80 & .545 & $37.7, \quad 73.3, \quad 51.4$ & 6 \\
\hline $200, \quad 80, \quad 60$ & .472 & $\begin{array}{lll}14.1, & 88.9, & 18.9\end{array}$ & 4 \\
\hline $50, \quad 80, \quad 30$ & .453 & $\begin{array}{lll}18.6, & 88.3, \quad 67.8\end{array}$ & 2 \\
\hline $20, \quad 80, \quad 60$ & .375 & $9.3, \quad 88.7, \quad 76.0$ & 6 \\
\hline $100, \quad 90, \quad 60$ & .335 & $34.0, \quad 78.9, \quad 52.0$ & 2 \\
\hline $280, \quad 90$ & .335 & $35.2, \quad 84.6, \quad 43.7$ & 1 \\
\hline
\end{tabular}

